\title{
The Role of the Teaching and Learning Center in Promoting Transformative Learning at a Metropolitan University
}

Judith Ableser and Christina Moore

\begin{abstract}
With many potential community partners and a diverse student population, the metropolitan university has many opportunities to operationalize transformative learning, which involves a dramatic shift in one's assumptions that has a lasting change on their perspectives. The challenge of identifying transformative learning initiatives and making these initiatives take hold across a campus requires administrative direction and faculty buy-in. A teaching and learning center (TLC) can guide and sustain such transformation by providing the pedagogical expertise to identify and evaluate transformative learning initiatives, offering a collaborative forum for implementing these initiatives, and serving as an embedded structure to protect initiatives over time. The literature on organizational change in higher education and transformative learning has not yet explored the role TLCs can have in these areas. This article offers a narrative of how a TLC promoted transformative learning through two initiatives: creating a Universal Design for Learning (UDL) initiative to had better include diverse learners, and increasing community engagement through collaborative interactions with the university's new Experiential Learning Center. This manuscript offers guidelines on leading, directly and collaboratively, such initiatives in a sustainable way, to assist other TLCs in meeting similar goals at their own metropolitan institutions.
\end{abstract}

Keywords: collaborative leadership; universal design for learning; community engagement; experiential learning; strategic planning; organizational change; change initiative

\section{Introduction}

Transformative learning involves a structural change, or paradigm shift, in the way students see themselves, and in their relationship to others, that involves disorienting dilemmas, critical reflection, rational dialogue, and action (Mezirow, 2000, 1991; Cranton, 2006; Cranton \& King, 2003). While transformative learning often focuses on the individual, it can also refer to the change process within a group such as a university that operate under "structures of assumptions" that shape their identities (Mezirow, 1997) and their "relationships to others, the community, and the environment” (University of Central Oklahoma, 2016). With potential community partners and a diverse student population, the metropolitan university often has opportunities to operationalize transformative learning, including high impact practices, embodied learning and other strategies toward improving student learning. This article explains how one teaching and learning center has both helped transformative learning practices take root at a metropolitan university and helped the university undergo a transformation.

The metropolitan university embraces the opportunities and challenges of serving its local communities, both by offering education to the city’s local population and by bringing the 
benefits of that education into the surrounding community (Laur, 2014). These missions make the metropolitan university a hub for diverse perspectives and community engagement, two opportunities for transformative learning experiences for students. Cultivating these two opportunities into transformative learning experiences requires institutional change, which must involve senior administration as well as representatives from across the campus. With frequent changes in senior administration and other institutional changes along the way, a mid-level center on campus can sustain university change initiatives (Kezar \& Eckel, 2002) and "assess the pulse of a campus" to be the driving force behind these initiatives (Andersen, 2008, p. 41). A teaching and learning center (TLC) can guide and sustain such transformation: it provides the pedagogical expertise to identify and evaluate transformative learning initiatives; it offers a natural collaborative forum for organizing and implementing these initiatives; and it serves as an embedded structure to protect initiatives despite turnover in senior administration. This article offers a description of how our TLC, located at a metropolitan university in Metro Detroit area, promotes transformative learning through two initiatives: creating a Universal Design for Learning (UDL) initiative to better include diverse learners and increasing community engagement through collaborative interactions with our university's new Experiential Learning Center. Guidelines and recommendations, outlined here, for how to lead such initiatives in a realistic and sustainable way will assist other TLCs to meet similar goals at their own metropolitan institutions.

First, the TLC must carefully assess the mission, culture, and resources of the university at large and create their own strategic plan accordingly. The strategic plan helps the TLC identify how it can promote transformative learning implicitly, through initiatives that create learning environments conducive to transformative learning, and explicitly, through initiatives that support proven modes of transformative learning. In this process, the TLC can identify ways to support transformative learning initiatives in two types of leadership roles: 1) a directive leader, who initiates and provides the primary resources for implementing an initiative, and 2) a collaborative leader, who identifies existing leaders and resources beyond the TLC and brings them together to streamline a collective effort. Our TLC's leaders are taking a directive leadership role in promoting a Universal Design for Learning (UDL) initiative. Universal Design for Learning implicitly promotes transformative learning by removing barriers to diverse learners and, therefore, improving opportunities for diverse perspectives to contribute ideas that challenge the norm. In addition, our TLC has taken a collaborative leadership role in our university's Community Engagement initiative, a more explicit mode for transformative learning.

\section{Background of Oakland University}

Oakland University itself has transformed into a more metropolitan, diverse, and community engaged institution. This Midwestern doctoral research institution began in 1957 as a land-grant satellite campus of Michigan State University - Oakland (MSUO). It became a standalone institution called Oakland University (OU) in 1963. Originally, the campus was a small, rural community with a student enrollment of approximately 1,500 (Oakland University, 2016). More than 50 years later, OU has grown to a student enrollment of just over 20,000 students (Oakland University, 2016). Its population of diverse students has also increased, but this diversity has seen more increase in its Asian and international populations and is still a predominantly white institution (76\%). Table 1, which compares OU’s Black and Hispanic population with Detroit 
and Pontiac, shows that while these two neighboring cities are comprised of Black residents (52\% in Pontiac and 82\% in Detroit), only 9\% of OU students identify as Black or African American.

Table 1. Demographics at OU Compared to Pontiac and Detroit

\begin{tabular}{|l|r|r|r|r|}
\hline & \multicolumn{1}{|c|}{ Oakland University } & \multicolumn{1}{c|}{ Pontiac } & \multicolumn{1}{c|}{ Detroit } \\
\hline Race/Ethnicity & $\mathbf{2 0 1 6}$ & $\mathbf{2 0 1 0}$ & $\mathbf{2 0 1 0}$ & \multicolumn{1}{c|}{$\mathbf{2 0 1 0}$} \\
\hline White & $76.1 \%$ & $81.2 \%$ & $34.4 \%$ & $10.6 \%$ \\
\hline Black, or African American & $8.8 \%$ & $9.3 \%$ & $52.1 \%$ & $82.7 \%$ \\
\hline Hispanic, or Latino & $3.3 \%$ & $2.3 \%$ & $16.5 \%$ & $6.8 \%$ \\
\hline
\end{tabular}

OU data collected from OU's Office of Institutional Research. Pontiac and Detroit data collected from the U.S. Census.

This small campus nestled in the countryside found itself surrounded by geographic and demographic change. While the auto industry that made Oakland University possible still thrives in the surrounding area, neighboring cities Detroit and Pontiac, are still recovering from industry changes. Poised to evolve in many ways, Oakland University is currently undergoing the task of deciding how it wants to transform with its surrounding area.

OU is a member of the Coalition of Urban and Metropolitan Universities (CUMU), whose members define themselves as diverse universities profoundly connected with their surrounding communities through partnerships, service, and resources (CUMUonline.org, n.d.). This is one step toward the university's mission to meet the Carnegie Community Engagement Classification, which it plans to do by better quantifying disparate community engagement already taking place on campus and adding signifiers such as CUMU membership and larger community initiatives.

Due to its location, student population growth, and increased investment in community engagement, Oakland University's recent strategic plan makes a commitment to a metropolitan focus, diverse perspectives and ideas, and community engagement for learning opportunities.

\section{Transformative Learning at a Metropolitan University}

Since transformative learning can happen in a variety of environments, it is important for metropolitan universities to identify the transformative learning practices that best fit their campus and community identity. Of the Declaration of Metropolitan Universities' six criteria for CUMU membership (Laur, 2014), our teaching and learning center (TLC) pinpointed two that are emphasized in our university's mission: enhancing student success for a diverse population and engaging with the community.

Cultivating diversity through a diverse student population and diverse learning opportunities (methods, curriculum, etc.) is essential to transformative learning experiences yet difficult to achieve fully. Higher education institutions continually struggle to take the value of diversity from talk and token cultural events to embedded change (Keating, 2007). As a primarily white institution, where underrepresented minorities make up 14 percent of the student population (Oakland University, 2016), the university is working to recruit more diverse students. But the 
full benefits of diversity must be embedded in practice as well as population (Nielsen, 2016). An important way to keep institutions accountable to diversity-related transformation is "to promote basic areas of excellence such as teaching and learning" (Anderson, 2008, p. 37), meaning that true diversity must permeate what takes place in the classroom. Such a classroom must "examine one's assumptions" and create space "to engage in challenging dialogue" (Nielsen, 2016, p. 53). It is also integral to define "diversity" in the broadest terms possible-race, sexual orientation, ethnicity, disability, among many others. As the authors will discuss in depth, Universal Design for Learning principles reduce barriers to learning differences and life needs that come with diverse students. Reducing such barriers frees students to engage in the difficult dialogues and dilemmas that is so integral for transformative learning.

While diversity-centered transformative learning focuses on what happens on the campus, community engagement reaches beyond the campus boundaries. As the most defining value of metropolitan universities (CUMU, 2016), community engagement is also a prominent part of our university's strategic plan —one of its three main goals. The university is currently working to better measure and organize its current community engagement work, such as service learning initiatives, community partnerships, course designs, to earn the Carnegie Foundation's Community Engagement Classification, a motivator driving engagement initiatives at many universities (Votruba et al, 2011). One embedded investment in community engagement came in the form of a new full-time Experiential Learning Coordinator hired in June 2016, along with the opening of the Experiential Learning Center in November 2016. Our institution has recognized the opportunities to connect more closely with the community to provide transformative learning experiences for our students. Our TLC is collaborating with the Experiential Learning Center to offer faculty ongoing professional development and services.

\section{The Teaching and Learning Center's Role}

Now that Oakland University has committed to student body diversity and community engagement through its mission, strategic plan, and resources, the challenge ahead is to fully implement these values in a way that, as the institution's primary goal states, will "foster student success through a robust teaching and learning environment” (Oakland University, 2015). The formal, initial support of these two values is not sufficient to ensure their success, as these changes take many years to become the fabric of an institution. A metropolitan university's TLC is often the best agent to assure these initiatives continue on their path toward transforming the university (Kezar \& Eckel, 2002), as its connection to faculty, staff, and senior administration helps it form productive, focused collaborations (English, 2013) and break down the silos that are often barriers to realizing change initiatives (Kezar, 2014). While TLCs have limited staff and resources, their formal structure and role on a metropolitan campus equip them to connect the university's initiatives to transformative learning practices and organize the campus community to sustain initiatives through their years of implementation.

\section{Developing a TLC Strategic Plan}

In light of our university's new mission statement and strategic plan, our TLC revisited our mission statement and created its own strategic plan to align directly with the three central goals in the university's strategic plan. Goal 1 in the strategic plan most aligned with the purpose of 
our TLC: "foster student success through a robust teaching and learning environment with comprehensive student services” (Oakland University, 2015). The center staff framed the strategic plan with student success at its core, by supporting the teaching and learning environment, and by collaborating with student services. For example, the center revised the teaching grant's criteria to focus on course redesign to increase student success and created workshops and programs with student-support services. Universal Design of Learning (UDL) is a strong example of this alignment.

The center also linked the other two goals of research excellence and community engagement whenever possible. For example, research excellence tied into the scholarship of teaching and learning (SoTL), which the center supports through grants, faculty development institutes, and other programming. SoTL satisfies both teaching and research excellence, as it is the work of faculty members collecting and disseminating data regarding what takes place in their courses. The university's third goal, focusing on community engagement, advances through OU's TLC's collaborative efforts with Experiential and Service Learning.

While the process was work-intensive and tedious, a challenge in a center comprised of one full time director, an office assistant and two part-time staff, it put into order all of the ad-hoc collaborations, goals, and resources we had accumulated in the five years since the TLC's opening. The reflection facilitated through this strategic plan led us to identify which transformative learning initiatives we could lead and how we would lead. As one of the smallest structures on campus, the TLC must be selective on what type of leadership it takes in university initiatives when it is already busy with its own programs and services. Our leadership style breaks down into two categories: directive leadership and collaborative leadership. In a directive leadership role, the TLC identifies a need or opportunity for transformative learning at its university and pulls together resources to implement the change at the institutional level, including resources coming from the TLC directly. In a collaborative leadership role, the TLC promotes initiatives taking place across campus and facilitates discussion among staff better equipped to lead actions and invest resources. It is possible that many TLCs should work predominantly in collaborative leadership roles and only take on directive leadership roles when the TLC’s resources can simultaneously meet the university and center needs.

\section{Universal Design for Learning: Implicitly Promoting Transformative Learning through Diversity}

Oakland University's Diversity Council seeks to promote student success and embrace inclusion and diversity. OU's TLC director, who serves on this council, explained to the council that Universal Design for Learning is a method for meeting these goals. With the endorsement of the Diversity Council, the TLC decided to take directive leadership of the Universal Design for Learning, a campus-wide initiative that not only supports but also capitalizes on learning differences in the classroom. In this way, the center implicitly promotes transformative learning by leading initiatives that improve learning for a diverse student body. Universal Design for Learning (UDL) is both a philosophical framework and set of guiding principles to increase access and reduce barriers to learning for diverse learners (CAST, 2016; Meyer, 2014; UDL Center, 2016). It gives more autonomy to students as to how they engage, demonstrate, and express what they have learned with more "flexible curricular materials” (Ouellett, 2004, p. 136). 
Its origins stem from architectural design and the Americans with Disabilities Act (ADA) but has since applied to educational contexts as well. For example, ramps may have been initially designed to give increased access to individuals in wheelchairs, yet all of us who have transported a baby in a stroller, pushed a shopping cart, or pulled luggage across an intersection have benefited from universal design.

UDL guidelines involve providing learners with multiple means of engagement, representation, and expression (Meyer, 2014). Examples might include providing opportunities to engage in both class and online activities, offering both visual and text examples, and providing flexibility in demonstrating learning outcomes. Flipped classrooms are a good example of a method for giving students agency over the lecture and content-delivery experience (Smith et al., 2015). In addition, video-recording classroom sessions allows for students to review the material after class and take further notes on content covered that they could not write down in the allotted time. This supports learning for a wide-range of diverse students including international, underperforming learners, struggling writers, and students with life needs that prevented them from attending a specific session.

UDL serves the diverse student body integral to a metropolitan university's identity (CUMU, 2014) by supporting diverse learning and life needs. Higher education's diverse student population includes a wide range of abilities, challenges, and experiences (e.g. international students, English language learners, veterans, introverts, students with anxiety, long-distance commuters, working students, or parents). From a social justice perspective, UDL principles and practices move beyond specific accommodations for those with identified disabilities toward supporting the much broader diverse population of today's students who attend metropolitan universities (Nielsen, 2016). For example, students from communities confronted with poverty and other social challenges meet significant barriers when arriving at our universities. Only 37\% of 12th grade students are reading at the proficient level (NAEP, 2015). UDL's inclusive practices can help support the large percentage of students who are non-proficient readers by offering guided reading with prompts and questions to focus readers' attention to the salient and central concepts and using video and multimedia to complement extensive reading. While not eliminating the need for ADA accommodations, it can reduce the barriers that often result in diverse students opting out of higher education.

Since transformative learning is associated with encountering disruptions and barriers, how does UDL promote transformative learning when UDL's main goal is to reduce barriers? The lies in what type of barrier a learner encounters, and what is available beyond that barrier. The learning barriers that diverse students encounter in traditional classrooms prevent access to engaging with course content. By removing these procedural barriers, UDL principles increase access for all types of learners, which increases access to the psychological barriers integral to transformative learning. Diverse students are able to focus less on remediation and more on sharing and questioning ideas. For example, by providing students the opportunity to participate in class discussions online in addition to the on-campus classroom, more students will have the opportunity to contribute ideas, pose questions, and share diverse perspectives that challenge one another's assumptions, whereas the traditional classroom discussion typically engages fewer student voices. Moreover, by giving students more agency in how they engage, represent, and express learning, UDL principles disrupt students' assumptions of how to learn and of their role 
in learning. Referring back to the example of an online discussion, students may experience disruption and dilemmas when asked to demonstrate their learning in a way other than a traditional essay, or peer review a student's work in an unfamiliar genre. UDL principles ensure that all students have access to transformative learning experiences by removing barriers to diverse students and expanding perspectives of how learning can occur.

As is always a threat to change initiatives related to diversity, it is important to emphasize that Universal Design Learning is a gateway to richer, better ways of learning for all students, not just an antidote to “inferior" learning styles or "deficit and remedial provision” (Ingleby, 2011; Higbee, Bruch \& Siaka, 2008). Beyond valuing tolerance and accommodation, UDL has the potential to provide "inclusionary frameworks" and "broader common ground" in the learning environment (Keating, 2007, p. 10), outcomes often lacking in diversity initiatives. Embracing diversity at an institutional level does not merely mean inviting minority students into majority cultural learning practices, but “widening participation” and "mainstreaming” diverse learning opportunities for all learners (Ingleby, 2011; Thomas, 2011). UDL is a way to show that diversity is deliberately central to courses rather than merely featured in cultural celebrations that co-exist with unchallenged ideologies (Keating, 2007; Anderson, 2008; Higbee, Bruch \& Siaka, 2008). UDL implicitly promotes transformative learning by challenging the ways students can consume, demonstrate, and apply course content.

\section{Operationalizing UDL at Our University}

Because we had finished our strategic plan in Winter 2016, we could assemble a university-wide team on Universal Design for Learning with enough time to research, discuss, and reflect on the opportunities and challenges for UDL at our university. From this point, our TLC could take a directive leadership role in the UDL campus initiative through the center's programming, information resources, and collaborators.

It is a relatively easy task for a TLC to provide workshops and training materials to introduce and teach faculty how to use UDL resources and techniques. It is a much more complex task to transform an institutional culture to accept and endorse such practices based on long-held assumptions about who should attend university and who should succeed. To promote change beyond cohorts of faculty, the center organized a UDL initiative team made up of faculty and students from different schools and staff from academic and student affairs including disability support services, office of diversity and inclusion, e-learning and technology services. This team explored ways in which UDL principles could become part of the institutional and classroom culture. By including this range of perspectives and expertise, the TLC facilitated "the crossfertilization of ideas" that "has often helped to encourage the exchange of ideas and to loosen tightly held assumptions” in higher education institutions (Kezar, 2014, p. 71). The team's goal was to study and learn more about UDL and then create a plan of how to introduce it to the campus at large. Each member of the team met with different groups and committees across campus to introduce and discuss the initiative.

The team discussed how faculty and the larger campus would receive UDL's principles. For example, some faculty might refuse to buy into recording their lectures. Underlying this issue are larger issues of faculty who view "their adopted disciplinary theories and pedagogical practices 
as largely immutable," therefore finding it unnecessary to "interrogate and question their own assumptions, practices, and the corresponding or associated effects” (Nielsen, 2016, p. 52). In this same vein, some faculty fail to "challenge underlying knowledge structures or conventional teaching methods” (Keating, 2007, p. 11). Any initiative to implement transformative learning structures in the classroom will require faculty to undergo the process of transformative learning as well by resolving a disorienting dilemma through rational dialogue and critical reflection. OU’s TLC set out to provide this opportunity through its programming and resources.

The team's work informed how we would organize some of our 2016-2017 programs around UDL. OU's TLC did this primarily through selecting a Faculty Fellow, a one-year post, to lead UDL initiatives such as a yearlong faculty development institute (FDI), a scholarship of teaching and learning (SoTL) grant, and a series of faculty workshops. The FDI structure brings together a cohort of faculty who want to study a teaching strategy to implement in their courses. FDIs often prepare faculty to apply for the center's SoTL grants, which provide faculty $\$ 3,000$ to create or redesign courses based on their research of higher education pedagogies and disseminate the results in a university session, conference presentation, or scholarly publication. Since these SoTL grants often include a university theme, this year's grant application invited proposals focused on UDL in addition to other student success strategies. Lower-commitment opportunities to talk about UDL include faculty workshops, which are open to the whole faculty, staff, and graduate student community. Since these are the TLC's established resources and programs, these efforts did not add extra work to our responsibilities.

In any effort to transform a university's culture, the common language used to communicate an idea is key (Kezar, 2014). The phrase "universal design for learning” appeared in programming, but TLC staff also wanted to emphasize its key points: (a) the university team connected to UDL; (b) UDL's link to student success; and (c) the resources available to faculty interested in evaluating their courses using UDL principles. A vital component of this UDL Faculty Development Institute is that it establishes a cohort of faculty who become "early adopters" of the initiative and can serve as ambassadors across the campus to help transform the culture. These ambassadors were equipped with UDL “Quick Notes," a series of visual, brief guides to UDL's core ideas and strategies. The TLC disseminated these to the entire university community in university electronic communications and made available on our website on a specific UDL page. Creating a foundational guide like this is a significant piece to ensuring institutional changes take hold (Kezar, 2014), and it ensured that all team and FDI participants used the same language and emphasizing the same points when sharing their work with other campus groups.

The transformative learning impact of UDL will be perceivable in the structure of class activities and assessment in the years to come. The implementation phase is only beginning, and TLC's future work will analyze the impact and results.

\section{Experiential Learning: Explicitly Promoting Transformative Learning through Community Engagement}

While OU's TLC made strategic efforts to initiate a campus-wide discussion about UDL, community engagement was an initiative already often discussed across campus. In the example of the UDL initiative, the TLC took a directive leadership role. Since larger university 
committees and sources beyond the TLC were leading community-engagement efforts, we took a collaborative leadership role with other centers and programs to promote community engagement through the lens of transformative learning.

Experiential Learning (EL) involves learning through direct experiences; learning by doing, and reflecting on those experiences (Moon, 2004). Kolb’s Experiential Learning Cycle (1986) provides the foundation for EL and includes the following four phases: having concrete experiences, reflective observation, abstract conceptualization, and active experimentation. In higher education, EL can link to the curriculum through Academic Service Learning, volunteering, observational visits, capstone projects, internships and other forms of civic engagement. Academic Service Learning (ASL), a common type of EL, involves achieving targeted course learning objectives by integrating meaningful community service and instruction and reflection to enrich the learning experience, teach civic responsibility and strengthen communities within credit-bearing courses (Furco, 1996; National Service Learning Clearinghouse, 2017). These community experiences provide robust opportunities for students to engage in transformative learning as they meet the challenge to see the world from a different and new perspective, which can create disorienting dilemmas requiring critical reflection, rational dialogue, and action (Mezirow, 2000, 1991).

This “experiential learning” category allows a university to better link community engagement to transformative learning theory, which research frames in the form of community-based learning (Castañeda, 2008; Roswell \& Davis, 2014), service learning (Bamber \& Hankin, 2011; Levkoe, Brail \& Daniere, 2014), and experiential learning (Isaacs, 2016; Zull \& Fried, 2012). Through these studies on transformations occurring through experiential learning, students report realizations on assumptions they never would have thought to question (Castañeda, 2008), facing their own biases of immigrant populations (Bamber \& Hankin, 2011), and the satisfaction of making real that which was learned hypothetically in the classroom (Isaacs, 2016; Zull \& Fried, 2012). A TLC's partnership with the university’s community engagement resources better ensures faculty and staff will know how to help their students recognize and reflect on the transformative learning taking place in their classroom and communities.

In the last 10 years, pockets of our university have pioneered academic service learning initiatives, from single course projects lasting no more than a semester to partnerships with high schools and nonprofit organizations still going strong and even growing. At one point the university had an Academic Service Learning “office,” staffed with a graduate assistant and parttime work from a faculty member (plus two faculty fellows), but the one-time grant funding on which this office depended did not allow it the physical and staffing resources needed to be sustainable. Years later, as the university named itself as a "preeminent metropolitan university" in its revised mission statement in 2015 and emphasized community engagement in its strategic plan, it established two large committees to determine how to bring together current community engagement efforts and built on these efforts. Currently, the president's webpage on the university's strategic plan highlights community engagement, listing several projects across campus but focusing on the OU-Pontiac Initiative, "a sustainable, mutually beneficial relationship" between the university and neighboring city of Pontiac (Oakland University, 2014). Pontiac, once a manufacturing center for the auto industry, has experienced shrinking infrastructure and poverty. OU's president has repeated “our work in Pontiac is vital to realizing 
our commitment to becoming a preeminent metropolitan university.” The OU-Pontiac Initiative lists two staff members dedicated specifically cultivating this initiative and 28 ongoing projects from across disciplines.

The OU-Pontiac Initiative is only one of many of other community engagement initiatives happening on campus falling under categories of service learning, internships, community education programs, and broader collaborations and partnerships. In order to accommodate disparate community engagement efforts through the lens of student learning, the university's committee on community engagement sought to put these efforts under the umbrella of “experiential learning,” hire a full-time Experiential Learning Coordinator to organize and develop these efforts (accomplished Summer 2016), and establish a physical Experiential Learning Center (ELC) (accomplished Fall 2016).

\section{Promoting Experiential Learning at Oakland University}

While the university is providing the resources and leadership to make community engagement flourish, a TLC can serve to help connect faculty to these community engagement resources and pave the way for faculty and student participation. Often missing from the communityengagement movement in higher education is the embedded academic home that makes it possible "to garner resources and foster internal mobilization events that spark dialogue, critique, and identity formation," bringing together all scholars involved with service learning at some level through curriculum development, hiring practices, and professional development (Butin, 2011, p. 23). OU's TLC sought to initiate opportunities for faculty to engage in Academic Service Learning prior to the establishment of the Experiential Learning Center and now collaborates on an ongoing basis with the EL Coordinator to facilitate dialogue and provide a forum for this professional development. At some institutions, the Experiential Learning Center (ELC) is part of the Teaching and Learning Center. At Oakland, Academic Affairs decided that it should reside in the Student Success Office. The main goals of this ELC is to make connections and partnerships in the community and be able to provide opportunities for students to have community-based experiences through academic service learning, internships, volunteering, capstone projects, or other forms of civic engagement. The Coordinator can work with faculty to help them design and develop service-learning courses and support and serve as a facilitator for community connections.

Prior to the establishment of the Experiential Learning Center, our TLC offered numerous workshops, discussion groups, learning communities, and teaching grants that focus on redesigning courses using Academic Service Learning to enhance student success. Our workshops have introduced the concepts and best practices for ASL and provided a case study and example of one very successful academic service-learning course developed by a faculty member. Our discussion groups, or Coffee and Conversations, have encouraged faculty to share their experiences, highlights and challenges of implementing it in their courses. Our yearlong learning community (LC) involves a cohort of faculty who are interested in gaining knowledge and skills in integrating Service Learning in a course. Over the year, they plan and develop strategies that they can implement. They meet regularly to share their experiences and problem solve their challenges. The facilitator of this LC is actively involved in using ASL in her courses and provides guidelines and suggestions. Each year our TLC offers teaching grants for faculty to 
redesign a course in order to enhance student success and engage in scholarship of teaching and learning by examining and reflecting on their own teaching practice and disseminating the results. Faculty have won numerous grants for focusing on developing, implementing and analyzing the impact of ASL.

Now that Oakland has fully implemented the ELC, there is ongoing collaboration between the TLC and the ELC to provide professional development across the campus. The ELC Coordinator will run a series of workshops each year at our TLC and provide support for faculty who are working on teaching grants that include an ASL component or other forms of EL. In addition, the coordinator sits on our TLC's Advisory Board and meets on an ongoing basis with our TLC's director to explore different opportunities and initiatives.

The challenge at this point is how to make sure our faculty know how to utilize the services available by having an ELC. In turn, the ELC's coordinator wants to better understand better the faculty's' needs and how he can work with them. Our institution's faculty operate under an assumption of taking on the full burden of experiential learning experiences, maybe with the help of their colleagues and department if experiential learning practices such as service learning, volunteering, and internships are regular practices. Since this is already a university-wide initiative, there is much to explore as to how community engagement via experiential learning will develop across schools and departments. Such widespread change happens slowly, even with increased resources on campus. As the TLC promotes community engagement, its members have to accept this slower pace of change and continue communication with the ELC and the faculty who are interested in helping facilitate transformative learning experiences through community engagement. Ongoing collaborative efforts between ELC and TLC to promote and support experiential learning resources, professional development, and other opportunities is enhancing transformative learning experiences at our institution.

\section{Recommendations for TLCs to Promote Transformative Learning at Metropolitan Universities}

“Transformative learning” often refers to learning opportunities for our students. Yet the journey that faculty, staff, and administrators must take to develop and implement transformative learning initiatives, such as UDL and Experiential Learning, is also a transformative learning opportunity. Creating a culture of UDL and Experiential Learning at a university requires a deep structural change, or paradigm shift, in the way faculty and students see themselves and their relationships with others that involves disorienting dilemmas, critical reflection, rational dialogue, and action (Mezirow, 1978; Cranton, 2006). UDL and Experiential Learning may require faculty to reconsider how they design activities, select texts, and assess learning outcomes - in short, the whole design of their teaching. The TLC can be a safe place to facilitate the dialogue and debate faculty need to undergo a transformation in how they teach.

Universal Design for Learning requires us to shed the view that only the "best and brightest" can succeed, and consider that all students have the right and potential to succeed if provided with increased access to diverse learning. Although many may support this belief, some still feel that universities should "weed" out students early who struggle, or else should not provide a range of choices and learning options. 
These difficult conversations need to take place in a safe and open environment with opportunities for debate and discussion grounded in evidence-based practice and effective, simple techniques for faculty to try to reflect upon, gradually.

Community engagement and experiential learning may also challenge our way of thinking and doing. Faculty have to relinquish control over the content and instruction and embrace learning outside of a classroom and a textbook. This may also involve faculty rethinking how they spend their time; moving away from preparing lecture notes toward making community connections for their students.

Most TLCs are charged with helping faculty rethink and design their courses to improve student learning and leading and participating in transformative learning initiatives can increase a TLC's impact on student learning. Considering the circuitous, intensive process of promoting transformative learning initiatives, it can help if a TLC has a list of recommendations to plot out this process. In light of our experience leading transformative learning initiatives in a directive leadership and collaborative leadership role, we suggest the following recommendations for how to promote most effectively transformative learning at your metropolitan universities.

1. Develop a strategic plan for the TLC that aligns with the university’s plan.

This serves as the definitive guide to how all of your actions should line up with your priorities. TLCs need this structure because the university often asks them to take on ad-hoc projects and duties needed by the university, which makes it easy for the TLC to be a center for doing everything without strategic direction. If you also want your TLC to effect permanent change in the university's teaching and learning culture, a strategic plan is required. Research other strategic plans online, talk with other TLCs about their strategic planning process, bring in other perspectives to help revise the plan, and have it on hand to give to senior administration.

2. Within the strategic plan, identify how the TLC can promote transformative learning both implicitly and explicitly.

What transformative learning methods best fit your institution's identity and resources? Which methods best fit your TLC's expertise, resources, and passion? These questions, along with the data in your strategic plan, can help you pinpoint the transformative learning initiatives upon which your center may want to act. Either the TLC can promote transformative learning explicitly by promoting practices specifically categorized as modes for transformative learning, or it can do so implicitly by improving conditions necessary to make these practices happen.

3. Decide whether the TLC's leadership will be in a directive or collaborative leadership role.

The collaborative leadership role should be the default role since a TLC's strengths and weaknesses best fit this role. Since most TLCs have very limited resources, the collaborative leadership role is important for achieving feasible change, identifying what other resources on campus can take the lead and providing support accordingly. Nevertheless, there are key opportunities to take the directive leadership role in a transformative learning initiative when the 
TLC can align its programs and services with that initiative and when no other area on campus is equipped to take the lead.

4. Follow research-based practices for institutional transformation to ensure transformative learning initiatives will take hold.

Institutional transformation undergoes similar challenges and realizes similar rewards to those found in transformative learning theory. Transforming a university built on a slow-to-change culture is challenging, especially changes that require shifts in underlying, firmly held attitudes. These "second order changes," as Kezar (2014) called them, are so challenging that the research on successful institutional transformation at this deeper level is limited and mostly consists of "cautionary tales" (p. 62). Fortunately, the impetus for higher education institutions means there is plenty of research on institutional change initiatives. Some of these strategies repeated throughout the research include taking stock of the university's mission and goals and gathering a committee and task force with broad campus perspectives to discuss challenges and make plans accordingly. Furthermore, communicate these plans to the larger public, allow plenty of time and open forums to make everyone heard, and invite individual units on campus to interpret initiatives in ways that fit their individual expertise and identity (Bolman \& Gallos, 2011; Kezar, 2014; Kezar \& Eckel, 2002; Thomas \& Tight, 2011). In addition to existing research on higher education change initiatives in general, seek out research about change relating to the specific initiative you have decided to pursue.

5. Move with participation from faculty, staff, and senior administration.

While senior administration can change at any point, it is important to have that powerful ally to make real change happen. The support of senior leadership is essential to institutional transformation, but the "quantum leaps" that make such transformation a reality "come from those at other levels of the organization who recognize and seek organizational change" (Andersen, 2008, p. 41). The other faculty and staff participants who are likely to stay at an institution longer are key to keeping momentum of an initiative going. Choose a variety of perspectives based on discipline and experience with innovative teaching and learning strategies. It is helpful to include perspectives of optimistic skeptics who can tap into the objections that will likely come up, along with the initiative’s natural champions.

6. Make this action visible.

The committees and task forces represent many perspectives on campus. Even if committee members have dutifully communicated their work to their respective departments, it is unlikely that all faculty and staff are aware of your initiative, or understand its importance. In order to continue the dialogue in a positive direction, the committee should plan how to inform the campus of this work. When your initiative groups are ready to share its core ideas and action plan, make guiding documents to disseminate to the entire campus. This is another key strategy toward institutional change, as it circulates the languages and ideas surrounding an initiative (Kezar, 2014). These should be brief, accessible, and mindful of your audience. Post them on your TLC's website, display them in print at the TLC's physical location (if one exists), and plan how you will promote them at related events on campus. Work with your senior administrator to 
plan how to deliver these guiding documents directly to each faculty and staff member through email or mailboxes. This dissemination of resources to campus community circulates the consistent language and ideas that are required to make cultural changes stick. It works best if these documents include an invitation to participate in related forums and professional development.

7. Foster the germination of ideas through professional development.

After all the committee's and task force's work on creating plans, much work remains to help faculty and staff members figure out what these plans mean for their departments, units, and individual courses: " $[\mathrm{M}]$ any of the important changes that are proposed within higher education will not occur unless sensemaking or organizational learning occurs" (Kezar, 2014, p. 82). This "sensemaking" process is circuitous, ongoing, and the critical step from turning plans into reality. Since the university is made up of autonomous bodies with disparate expertise and goals, sensemaking provides the structure and support to decide what these changes look like in their corner of the campus. This applies to optimists and skeptics alike.

Following transformative learning theory, help skeptics recognize disorienting dilemmas, facilitate rational dialogue, and critically reflect accordingly by inviting the campus community to open forums or through planned programming at the TLC. When facilitating transformative learning, whether in a classroom or faculty workshop, it is important to help learners move from reacting skeptically to uncertainty to transforming that uncertainty into a focused inquiry (English, 2013, p. 92). Because the most vocal resistance often comes from those whose “cognitive schema” doesn't accurately comprehend the initiative (Kezar, 2014, p. 48), offering faculty professional development opportunities to learn about the initiative and work toward understanding improves the chances of gaining broader support. By facilitating a productive dialogue while teaching faculty about the research supporting the initiative, you increase the likelihood for acceptance, support, and implementation.

8. Allow for time and patience, both from others and from yourself.

It is easy to feel that once your committee has thoroughly researched and discussed the initiative and the task force has determined reasonable steps forward, the hard work is in the past. In reality, getting input from the campus community, revising plans accordingly, and working with individual units to execute plans is the longest part of the process. Most higher education institutions do not allow for mandating changes down to every campus employee, and even if they do, such mandates would be impossible with the disparate roles and identities across campus. Every unit must find its own way to enact the initiative, a process the literature refers to as "sensemaking" (Kezar \& Eckel, 2002; Kezar, 2014). The range of time the whole process takes can range from 3-5 years, sometimes longer, and throughout the process, there could be points where the initiative is at a standstill. While persistence is important to keep action moving, be mentally prepared for a long process. Do not let frustration paralyze your motivation, sow doubt in your work, or rush to assign blame to one person or group. Use moments of frustration to reflect on the process and determine whether delays are normal or require new action. Even if all campus members are allies to your initiative, lasting implementation will be years in the making. 
9. Embrace the process of transformation as an outcome in and of itself.

Allowing for time and patience is easier when you embrace the journey of transformation itself. It is not a stagnant point in time but a recursive process in and of itself. The definition of the word "transformation" often includes the "process of changing" which suggests an ongoing, continual evolution. The awareness of the dilemmas, the critical reflection, and rational dialogue can create a rich experience for ongoing transformation that can keep us engaged and connected to the process.

10. Transformative learning is not only for students; it can enrich the professional thinking and action of all faculty and staff on campus.

Transformative learning challenges, and yet benefits not only students, but all members of a campus community. Faculty, staff and administrators can enhance their own beliefs and practice through ongoing critical reflection, rational dialogue and action, ultimately transforming the campus experience for all.

\section{Conclusion}

Transformation, by its very definition involves some kind of change. Humankind is often resistant to change, fearful of the loss of control, uncertainty, feelings of the unknown, concern of our level of competency, potential for more work, resentment and the difficulty breaking old habits. The TLC can address these concerns with evidence and research-based practice and can help faculty and staff develop practical alternatives and solution. 


\section{References}

Anderson. J. A. (2008). Driving change through diversity and globalization; Transformative Leadership in the Academy. New York: Stylus

Bamber, P., \& Hankin, L. (2011). Transformative learning through service-learning: No passport required. Education \& Training, 53(2), 190-206. https://doi.org/10.1108/00400911111115726

Brookfield, S. (2016). Keynote Address. Presented at theTransformative Learning Conference. University of Central Oklahoma, Edmond, Oklahoma.

Butin, D. W. (2011). Service-learning as an intellectual movement: The need for an "academic home” and critique for the community engagement movement. In T. Stewart \& N. Webster (Eds.), Problematizing service-learning: Critical reflections for development and action. (1935). Charlotte, NC: Information Age Publishing.

CAST, or Center for Applied Special Technology. (2016). About universal design for learning Retrieved from http://www.cast.org/udl/index.html

Castañeda, M. (2008). Transformative learning through community engagement. Latino Studies, 6(3), 319-326. https://doi.org/10.1057/lst.2008.35

Cranton, P. (2006) Understanding and Promoting Transformative Learning: A Guide for Educators of Adults (2nd ed.). San Francisco, CA: John Wiley \& Sons, Inc.

Cranton, P., \& King, K. P. (2003). Transformative learning as a professional development goal. New Directions for Adult and Continuing Education, 98, 31-37. https://doi.org/10.1002/ace.97

CUMU, (2016). Coalition of Urban and Metropolitan Universities [webpage]. Retrieved from http://www.cumuonline.org/

English, A. R. (2013). Discontinuity in learning: Dewey, Herbart, and education as transformation. New York, NY: Cambridge University Press.

https://doi.org/10.1017/CBO9781139177825

Furco, A. (1996). Service-learning: a balanced approach to experiential education In Taylor, B. and Corporation for National Service (Eds.), Expanding Boundaries: Serving and Learning (pp. 2-6). Washington, DC: Corporation for National Service.

Higbee, J. (2008) Institutional transformation: Some concluding thoughts. In Goff, E., \& Higbee, J. L. (Eds.). (2008). Pedagogy and student services for institutional transformation:

Implementing universal design in higher education. Minneapolis: Center for Research on Developmental Education and Urban Literacy, University of Minnesota.

Higbee, J., Bruch, P., \& Siaka, K. (2008) Disability and diversity: Results from the multicultural awareness project for institutional transformation. In Goff, E., \& Higbee, J. L. (Eds.). (2008). 
Pedagogy and student services for institutional transformation: Implementing universal design in higher education. Minneapolis: Center for Research on Developmental Education and Urban Literacy, University of Minnesota.

Higbee, J. L. \& Goff, E., (Eds.). (2008). Pedagogy and student services for institutional transformation: Implementing universal design in higher education. Minneapolis: Center for Research on Developmental Education and Urban Literacy, University of Minnesota.

Ingleby, A. (2011). Mainstreaming widening participation: Institutional transformation from small beginnings. In L. Thomas \& M. Tight (Eds.), Institutional transformation to engage a diverse student body. (97-106). Bingley, United Kingdom: Emerald Books.

Isaacs, S. (2016). Transformative learning: Postgraduate students' reflections on a community engagement program in South Africa. Social Behavior and Personality, 44(1), 103-115. https://doi.org/10.2224/sbp.2016.44.1.103

Keating, A. (2007). Teaching transformation: Transcultural classroom dialogues. New York: Palgrave Macmillan. https://doi.org/10.1057/9780230604988

Kezar, A. (2014). How colleges change. New York: Routledge.

Kezar, A. \& Eckel, P. (2002). Examining the institutional transformation process: The importance of sensemaking, interrelated strategies, and balance. Research in Higher Education, 43(3), 295-328. Retrieved from http://www.jstor.org/stable/40196456

https://doi.org/10.1023/A:1014889001242

Kolb, D (1984). Experiential Learning as the Science of Learning and Development. Englewood Cliffs, NJ: Prentice Hall.

Krause, K. D. (2011). Transforming the learning experience to engage students. In L. Thomas \& M. Tight (Eds.), Institutional transformation to engage a diverse student body. (199-212). Bingley, United Kingdom: Emerald Books.

Laur, B. (2014). Strategic action plan 2014-2017. Coalition of Urban and Metropolitan Universities [webpage]. Retrieved from

http://c.ymcdn.com/sites/www.cumuonline.org/resource/resmgr/Files/Business_Plan_v7.pdf

Levkoe, C. Z., Brail, S., \& Daniere, A. (2014). Engaged pedagogy and transformative learning in graduate education: A service-learning case study. Canadian Journal of Higher Education, 44(3), 68-85. Retrieved from https://files.eric.ed.gov/fulltext/EJ1049392.pdf

Meyer, A., Rose, D. H., \& Gordon, D. (2014). Universal design for learning: Theory and Practice. Wakefield, MA: CAST Professional Publishing.

Mezirow, J. (1991). Transformative dimensions of adult learning. San Francisco, CA: JosseyBass. 
Mezirow, J. (1997). Transformative learning: Theory to practice. New Directions for Adult and Continuing Education, 74, Retrieved from 5-12. Retrieved from

http://www.hrdmax.com/images/column_1325932983/Mezirow\%20Transformative\%20Learnin g.pdf https://doi.org/10.1002/ace.7401

Mezirow, J. (2000). Learning as transformation: Critical perspectives on a theory in progress. San Francisco: Jossey Bass.

Moon, J. (2004). A handbook of reflective and experiential learning: Theory and practice. London: Routledge Falmer.

National Assessment of Educational Progress: NAEP (2016). Retrieved from http://nces.ed.gov/nationsreportcard/

National Center on Universal Design for Learning (2016). Retrieved from http://www.udlcenter.org/aboutudl/udlguidelines_theorypractice

National Service Learning Clearinghouse (2017). Retrieved from https://gsn.nylc.org/clearinghouse

Nielsen, K. L. (2016). Whose job is it to change? New Directions for Teaching and Learning, 2016(147), 47-55. https://doi.org/10.1002/tl.20198

Oakland University. (2014). Pontiac Initiative: Why Pontiac? Why OU? Why now? Retrieved from https://www.oakland.edu/president/strategic-planning/pontiac-initiative/

Oakland University. (2016). About OU and OU students: Student profile fall 2016. Retrieved from https://www.oakland.edu/oira/about-ou-students/

Ouellett, M. L. (2004) Faculty development and Universal Instructional, Design, Equity \& Excellence in Education, 37(2), 135-144, https://doi.org/10.1080/10665680490453977

Roswell, B. S. \& Davis, S. W. (Eds.) (2013). Turning teaching inside out: A pedagogy of transformation for community-based education. Palgrave Macmillan. Retrieved from http://ebookcentral.proquest.com.huaryu.kl.oakland.edu/lib/oakland/detail.action?docID=158895 0

Thomas, L. (2011). Institutional transformation to mainstream diversity. In L. Thomas \& M. Tight (Eds.), Institutional transformation to engage a diverse student body. (77-96). Bingley, United Kingdom: Emerald Books.

United States Census Bureau. (2010). U.S. Department of Commerce. Retrieved from http://www.census.gov/quickfacts/table/PST045215/2665440,2622000 
University of Central Oklahoma. (2016). Center for Excellence in Transformative Teaching and Learning. Retrieved from http://www.uco.edu/academic-affairs/cettl/cettl-tl/index.asp.

Vidaček-Hainš, V., Divjak, B., \& R. Horvatek. (2011). Mainstreaming blended learning to enhance the access, learning and retention of students from equity groups. In L. Thomas \& M. Tight (Eds.), Institutional transformation to engage a diverse student body. (235-243). Bingley, United Kingdom: Emerald Books. https://doi.org/10.1108/S1479-3628(2011)0000006023

Zull, J. E. \& Fried, J. (2012) Transformative learning through engagement: Student affairs practice as experiential pedagogy. Stylus Publishing. Retrieved from http://www.ebrary.com.huaryu.kl.oakland.edu 


\section{Author Information}

Judith Ableser is the Director of the Center for Excellence in Teaching and Learning (CETL) at Oakland University. Her PhD is in Curriculum and Instruction from Wayne State University. Prior to serving as Director of CETL, she was an Associate Professor in Teacher Education focusing on meeting diverse learning needs of students and evidence-based practices in teaching and learning.

* Judith C. Ableser

Center for Excellence in Teaching and Learning

Oakland University

275 Varner Drive

Rochester, Michigan 48309

Email: ableser@oakland.edu

Telephone: 248-370-2455

Christina Moore is the Virtual Faculty Developer at CETL at Oakland University. Her undergraduate and graduate degrees are in English from Oakland University. Prior to her role at CETL, she was a Special Lecturer in Writing and Rhetoric. She has published in areas of learning technology, high impact practices, and teaching writing in higher education.

Christina M. Moore

Center for Excellence in Teaching and Learning

Oakland University

275 Varner Drive

Rochester, Michigan 48309

Email: cmamoore@oakland.edu

Telephone: 248-370-2499

*Corresponding author 